\title{
Monthly day/night changes and seasonal daily rhythms of sexual steroids in Senegal sole (Solea senegalensis) under natural fluctuating or controlled environmental conditions
}

\author{
Catarina Oliveira ${ }^{\mathrm{a}}$, Luísa M. Vera ${ }^{\mathrm{ab}}$, José F. López-Olmeda ${ }^{\mathrm{a}}$, José M. Guzmán ${ }^{\mathrm{c}}$, Evaristo \\ Mañanós ${ }^{c}$, Jesus Ramos ${ }^{c}$, F. Javier Sánchez-Vázquez ${ }^{\mathrm{a} *}$. \\ ${ }^{a}$ Department of Physiology, Faculty of Biology, University of Murcia. Spain. \\ ${ }^{\mathrm{b}}$ Reproduction and Genetics Group, Institute of Aquaculture, University of Stirling, UK. \\ ${ }^{\mathrm{c}}$ Department of Fish Physiology and Biotechnology, Institute of Aquaculture of Torre la Sal, \\ Spanish Council for Scientific Research (CSIC), Castellón, Spain.
}

\footnotetext{
* Corresponding Author:
}

Dr. F. Javier Sánchez Vázquez

Department of Physiology, Faculty of Biology

University of Murcia, Campus Espinardo

30100 Murcia, SPAIN

javisan@um.es

\section{Abstract}

Research on sexual steroids has usually focus on seasonal changes, but little attention has been paid to the existence of daily rhythms. A better knowledge of such daily fluctuations is required to asses accurately their plasma concentrations. To this end, in this paper we described the monthly day/night concentrations and seasonal daily rhythms of plasma sexual steroids (17 $\beta$-estradiol, $\mathrm{E}_{2}$ and testosterone, $\mathrm{T}$ ) in Senegal sole females, reared under natural photo- and thermo-period. In addition, the influence of the natural annual fluctuation of the water temperature on the plasma concentration of these steroids was investigated, using one group of Senegal sole under a natural photoperiod, but with an attenuated thermal cycle (around $17-20{ }^{\circ} \mathrm{C}$ ) for one year. No significant day/night differences were detected in monthly samplings, but the existence of an annual rhythm of $E_{2}$ and $T(p<0.01)$ with an acrophase in February was revealed by COSINOR analysis. Maximum values were reached in 
March for both steroids $\left(6.1 \pm 1.7 \mathrm{ng} \mathrm{ml}^{-1}\right.$ at mid-dark, MD and $4.0 \pm 0.6 \mathrm{ng} \mathrm{ml}^{-1}$ at mid-light, ML for E2 and $1.4 \pm 0.4 \mathrm{ng} \mathrm{ml}^{-1}$ at $\mathrm{MD}$ and $0.8 \pm 0.1 \mathrm{ng} \mathrm{ml}^{-1}$ at ML for T) in anticipation of the spawning season (May-June). As regards seasonal daily rhythms, at the spring solstice $\left(21^{\text {st }}\right.$ March) a daily rhythm was observed for both steroids (COSINOR, $\mathrm{p}<0.01$ ), with an acrophase at 20:00 $\mathrm{h}\left(\mathrm{E}_{2}\right)$ and at 21:08 $\mathrm{h}(\mathrm{T})$. When Senegal sole females were submitted to an attenuated annual thermal cycle, the steroid rhythm disappeared (there was no surge in spring, as in the control group) and these fish did not spawn, despite being subjected to natural photoperiod conditions. This result underlined the importance of the natural annual fluctuation of water temperature and photoperiod on the synchronization of the spawning season and on the onset of steroidogenesis.

Key words: Sexual steroids, 17 $\beta$-estradiol, testosterone, day/night concentrations, annual rhythm, seasonal daily rhythms, temperature, Solea senegalensis female.

\section{Introduction}

The biological rhythms in animals are synchronized by external factors, light being one of the most important. In most fish species from temperate zones, the seasonally changing pattern of daylength seems to be the responsible for the cuing and timing of reproduction. In salmonids, the predominant environmental cue for timing reproduction and spawning is the photoperiod (Bromage et al., 2001), whereas in many cyprinids, the predominant environmental cue is temperature and photoperiod combined (Hontela and Stacey, 1990). Seasonal changes in both photoperiod and temperature are transduced by the pineal organ into melatonin rhythm (producing high levels during the night and low levels during the day) which works as a Clock/Calendar signal. The nocturnal increase lasts longer under a short than under a long photoperiod, the photoperiod signals being transduced by melatonin (Reiter, 1993; Lincoln, 2006), which acts on the hypothalamic-pituitary-gonad axis (Amano et al., 2000; Bromage et al., 2001; Bayarri et al., 2004b; Falcon et al., 2007). This axis, in turn, controls reproduction timing and by means of neuroendocrine signals, regulates the production of sexual steroids and growth factors in the gonads.

Nevertheless, reproduction can not be considered an exclusively annual phenomenon, since daily changes in oocyte maturity and in the secretion of sexual steroids or gonadotropins have been described in species such as red seabream, Pagrus major (Matsuyama et al., 1988), snapper, Pagrus auratus (Carragher and Pankhurst, 1993), kisu, Sillago japonica (Kobayashi 
et al., 1988) and European sea bass, Dicentrarchus labrax (Bayarri et al., 2004b).

68 Furthermore, the effect of lunar cycle on reproduction has also been observed in various species of rabbitfishes (Takemura et al., 2004), in gilthead seabream, Sparus aurata (Saavedra and Pousão-Ferreira, 2006) and in Senegal sole, Solea senegalensis (Oliveira et al., 2008).

In females, sexual steroids are produced in the ovary and act both on the brain and the pituitary to regulate luteinizing hormone $(\mathrm{LH})$ release through a combination of positive and negative feedback actions (Yaron et al., 2003). Studies in goldfish suggest that elevated levels of both testosterone $(\mathrm{T})$ and $17 \beta$-estradiol $\left(\mathrm{E}_{2}\right)$ are important in the induction of the preovulatory LH surge (Kobayashi et al., 1989). Concentration of gonadal steroids in the blood stream provides information about the status of the brain-pituitary-gonad (BPG) axis and therefore, its measurement, is a useful tool to assess the reproductive status of the animal (Merson et al., 2000).

The Senegal sole (Solea senegalensis) is a species of high commercial interest, and the object of investigation by several groups in Europe. Spawning season takes place mainly in spring, with a secondary spawning in autumn (Anguis and Cañavate, 2005). However, one of the curbs on its production in captivity is the lack of control of its reproduction rhythms. Water temperature seems to play a crucial role in the reproductive cycle of both Solea senegalensis (Dinis et al., 1999; Anguis and Cañavate, 2005; García-López et al., 2006a) and Solea solea (Baynes et al., 1993), acting on gamete maturation, ovulation and spawning (Anguis and Cañavate, 2005). In Senegal sole recent studies have focused at sexual steroids, vitellogenin levels and gonad development (Aguillero et al., 2006; García-López et al., 2006a; García-López et al., 2006b; García-López et al., 2007; Guzmán et al., 2008), and melatonin rhythms and the influence of environmental factors, such as the characteristics of light and the temperature, on these rhythms (Bayarri et al., 2004a; Vera et al., 2007; Oliveira et al., 2007), but no evidences has been offered concerning the existence of changes in plasma steroid concentrations during the day in different seasons. A better knowledge of such daily changes is needed to avoid misinterpretation of the data when studding steroid levels in fish, since different values may be obtained if sampling takes place at different moments of the day.

To this end, we investigated monthly day/nigh changes in $17 \beta$-estradiol $\left(\mathrm{E}_{2}\right)$ and testosterone $(\mathrm{T})$ concentrations, and seasonally (during both solstices and equinoxes) the existence of daily rhythms in the levels of these hormones in female Senegal sole maintained under natural conditions of photo- and thermo-period. In addition, the role of the natural annual fluctuation of the water temperature in annual steroid rhythm synchronization is observed. 


\section{Material and Methods}

\section{Animals and housing}

For this study two different groups of Senegal sole from the same lot of an F1 generation with 4 years of age were used $(n=120)$. Both groups were maintained in similar rearing conditions, differing only in the water temperature regimen, which was the environmental factor we most wanted to test. Although both groups were not kept in the same place, the latitude was similar and the photoperiod conditions were exactly the same, so that the comparison can be regarded as reliable.

The first group, composed of 60 fish with a mean body weight of 1,369.1 $\pm 32.4 \mathrm{~g}$ and a mean body length of $43.3 \pm 0.2 \mathrm{~cm}$, was reared in the facilities of the research centre "Instituto de Acuicultura de Torre la Sal" (IATS) $\left(40^{\circ} 6\right.$ 'N, $0^{\circ} 9^{\prime} \mathrm{E}$, Castellón, Spain), in cylindrical 3,000 L tanks equipped with egg collectors. The water was provided in a constant flow of running marine water from the Mediterranean Sea, with a natural annual cycle of temperature. The tanks were covered with a raffia cloth, which provided a natural photoperiod, with maximum light intensity of 600 lux at the water surface during the day. Fish were fed ad libitum in the morning five days a week, using a dry pellet (ProAqua) feed and natural food, consisting of chopped fresh mussels and frozen squid.

The second group consisted of 60 Senegal sole with a mean body weight of $1,039.5 \pm$ 39.3 g. Fish were reared in a local fish farm, Piscimar S.L. $\left(39^{\circ} 53^{\prime} \mathrm{N}, 0^{\circ} 5^{\prime} \mathrm{E}\right.$, Castellón, Spain), in a cylindrical $16,000 \mathrm{~L}$ tank equipped with an egg collector. The water temperature fluctuation in this case was minimal $\left(17-20^{\circ} \mathrm{C}\right)$, since water was provided from a well, whose water temperature was almost constant throughout the year. The tank was placed in the outside, and the $90 \%$ of the surface was covered with a grey plastic cloth; there was a natural photoperiod, with a maximum light intensity of 870 lux at the surface of the water, during the day. The feeding regime was comprised of five weekly meals of mussels and squids and two of a dry pellet (ProAqua) feed, both ad libitum.

In both groups sole were individually labelled with an internal passive integrated transponder (PIT) tag system, enabling identification of each fish in repeated samplings. The egg collectors of both groups were checked daily to verify the presence of eggs, and on spawning days, the total number of eggs was estimated volumetrically.

Handling of the fish was in accordance with the European Union Directive (EEC, 1986) for the protection of animals used for experimental and other scientific purposes. 


\section{Experimental design}

Experiment 1: Monthly day/night differences in plasma sexual steroids $\left(E_{2}\right.$ and $\left.T\right)$

This experiment was intended to ascertain whether day/night differences in the plasma concentration of sexual steroids $\left(E_{2}\right.$ and $\left.T\right)$ existed in Senegal sole female, and how they varied during the year in natural conditions of temperature and photoperiod. For this, 12 sole (7 female and 5 male) from the first group (IATS) were used. Female were blood sampled around the $25^{\text {th }}$ of each month for a year (except July and October due to the incidence of bacterial infection in the broodstock), at Mid-Dark (MD) and at Mid-Light (ML). During the dark phase, sampling was carried out under a dim red light and after covering the fish head with aluminium foil. Sole were previously anesthetized with 2-phenoxyethanol $\left(0.5 \mathrm{ml} \mathrm{L}{ }^{-1}\right)$, individually weighed and identified with a "pit-tag" lector, and then sampled by caudal puncture, with $1 \mathrm{ml}$ heparinized syringe. Blood was collected in heparinized ependorf tubes on ice, and later centrifuged $\left(3,000 \mathrm{~g}, 4^{\circ} \mathrm{C}, 15 \mathrm{~min}\right)$ to separate plasma samples, which were frozen at $-20{ }^{\circ} \mathrm{C}$.

Spawning was monitored by collecting eggs, which were classified as viable (floating) or not. Viable eggs were incubated in $5 \mathrm{~L}$ sieves submerged in $250 \mathrm{~L}$ tanks of filtered and aerated sea water maintained between 16 and $18{ }^{\circ} \mathrm{C}$.

\section{Experiment 2: Daily rhythms of plasma sexual steroids $\left(E_{2}\right.$ and $\left.T\right)$ in different seasons}

This experiment set out to describe the seasonal differences in daily rhythms of plasma $\mathrm{E}_{2}$ and T. For this, 48 soles also from the first group (IATS), were used. Sampling took place at both equinoxes (March $20^{\text {th }}$, spring equinox and $22^{\text {nd }}$ September, autumn equinox) and at both solstices (June $21^{\text {st }}$, summer solstice, and December $21^{\text {st }}$, winter solstice). In each of these days, four to six female were blood sampled every three hours until a $24 \mathrm{~h}$ cycle was complete. The same fish were not sampled twice and they were transferred to a recovery tank after blood collection. The procedure of sampling was the same as described above.

\section{Experiment 3: Influence of an attenuated thermal cycle on the seasonal production of} plasma sexual steroids $\left(E_{2}\right.$ and $\left.T\right)$

To study the importance of the natural fluctuation of temperature during the year in the annual steroid rhythm in Senegal sole female, the second group of fish (PISCIMAR, S.L.)

166 was reared under an attenuated water temperature cycle throughout the year $\left(17-20^{\circ} \mathrm{C}\right)$.

167 Special care was taken to maintain similarity in the rearing conditions (e.g. photoperiod, sex- 
ratio, feeding regimen) between this group and the control group, to avoid introducing disrupting factors to the results. In each season, four to six females were blood sampled (as described before) at MD and ML. Then, the values of plasma concentration of $E_{2}$ and $T$ were compared with those obtained in the same month in the first experiment, in order to determine whether rhythms persisted in the absence of temperature synchronization.

\section{Data analysis}

\section{Sex Steroid ( $E_{2}$ and $\left.T\right)$ ELISA}

In order to assess the plasma concentrations of $E_{2}$ and $T$, samples were analysed in the facilities of the research institute IATS, by enzyme-linked immunosorbent assay (ELISA) using a protocol previously validated for Senegal sole plasma samples (Guzmán et al., 2005; Guzmán et al., 2008).

Sex steroids were first extracted in ice cold methanol and then reconstituted in $120 \mu 1$ of potassium phosphate buffer $(0.1 \mathrm{M}, \mathrm{pH} 7.4)$, and stored at $-20^{\circ} \mathrm{C}$ for analysis. In the steroid ELISA, microtiter plates (Maxisorp, 96-well microplates, Nunc) were coated with mouse antirabbit IgG monoclonal antibody (Cayman Chemical) and incubated (overnight at $4{ }^{\circ} \mathrm{C}$ ) with the following mixture (0.2 $\mathrm{ml}$ per well): standard $\left(\mathrm{E}_{2}\right.$ and $\left.\mathrm{T}\right)$ (Sigma-Aldrich) or sample, specific steroid antibody and the acetylcholinesterase tracer (Cayman Chemical). Colour development was then achieved by addition of Ellman's reagent in complete darkness at room temperature for $4 \mathrm{~h}$ and the absorbance measured at $405 \mathrm{~nm}$, using a microplate reader. The sensitivities of the ELISAs were $5.19 \mathrm{pg} \mathrm{ml}^{-1}$ and $8.78 \mathrm{pg} \mathrm{ml}^{-1}$ for the $\mathrm{E}_{2}$ and T ELISA, respectively. The intra- $(\mathrm{n}=4)$ and inter-assay $(\mathrm{n}=8)$ coefficients of variation $(\mathrm{CV} \%)$, at $50 \%$ binding, were $5.8 \%$ and $6.3 \%$ for $\mathrm{E}_{2}$ and $6.1 \%$ and $11.3 \%$ for T ELISA (Guzmán et al., 2008).

\section{Statistical analysis}

Statistical tests were performed using Excel ${ }^{\circledR}, \operatorname{SPSS}^{\circledR}$ and a Chronobiology software ("El Temps", by Prof. Díez Noguera, University of Barcelona, Spain).

Data are expressed as mean \pm standard error of the mean (S.E.M.). To determine the existence of significant differences in the plasma concentration of $E_{2}$ and $T$ between sampling points, data were subjected to one-way ANOVA, followed by a Duncan post hoc test (with a degree of significance of $\mathrm{p}<0.05)$. To determine the significance of annual and daily sex steroid rhythms, the COSINOR analysis was used. This analysis calculated the sinusoidal function that fitted our data, in which the mesor is the mean value around which the variable 
oscillates, the amplitude the oscillation between the mesor and the maximum value, and the acrophase the moment when the function reaches its maximum (Díez, 2007).

The ELISA data analysis was performed according to Guzmán et al. (2008).

\section{Results}

\section{Experiment 1: Monthly day/night differences in plasma sexual steroids $\left(E_{2}\right.$ and $\left.T\right)$}

In the first experiment, which aimed to investigate differences in steroid plasma concentrations between day and night during one year, the results pointed to no such fluctuations in either $E_{2}$ or $T$, although a significant annual rhythm was observed for both steroids. Maximal concentrations for both $\mathrm{E}_{2}$ and $\mathrm{T}$ were obtained in spring, before spawning period. In the case of $E_{2}$ (Fig. 1a), in the first sampling months (December and January) the plasma concentrations remained low both for MD and ML (around $1.1 \pm 0.2 \mathrm{ng} \mathrm{ml}^{-1}$ ). In February they started to increase, reaching a maximum in March $\left(6.1 \pm 1.7 \mathrm{ng} \mathrm{ml}^{-1}\right.$ at MD and $4.0 \pm 0.6 \mathrm{ng} \mathrm{ml}^{-1}$ at ML). In April, the values started to fall again, reaching a minimum in August $\left(0.3 \pm 0.3 \mathrm{ng} \mathrm{ml}^{-1}\right.$ at $\mathrm{MD}$ and $0.2 \pm 0.1 \mathrm{ng} \mathrm{ml}^{-1}$ at ML), when water temperature was highest, remaining low the rest of the months. Statistically significant differences among sampling months were found, but not between ML and MD samplings within the same month (ANOVA, Duncan's test, $\mathrm{p}<0.05$ ). The COSINOR analysis revealed the existence of a significant sinusoidal rhythm of annual plasma $E_{2}$ in female sole $(p<0.01)$, with a mesor of 1.4 $\mathrm{ng} \mathrm{ml} \mathrm{l}^{-1}$, an amplitude of $1.5 \mathrm{ng} \mathrm{ml}^{-1}$ and an acrophase in February (fig 1 $\mathrm{c}[\mathrm{c} 1]$ ).

The values of $\mathrm{T}$ for samplings varied between 0.1 and $1.4 \mathrm{ng} \mathrm{ml}^{-1}$ (fig $1 \mathrm{~b}$ ). The rhythm was similar to that of $\mathrm{E}_{2}$, the difference in this case being that the concentrations started to rise one month earlier, in January $\left(0.8 \pm 0.2 \mathrm{ng} \mathrm{ml}^{-1}\right.$ at $\mathrm{MD}$ and $0.9 \pm 0.4 \mathrm{ng} \mathrm{ml}^{-1}$ at ML). Values remained high until March $\left(1.4 \pm 0.4 \mathrm{ng} \mathrm{ml}^{-1}\right.$ at $\mathrm{MD}$ and $0.8 \pm 0.1 \mathrm{ng} \mathrm{ml}^{-1}$ at ML), and in April started to descend. During the rest of the months $T$ remained basal. Statistically significant differences among sampling months were found, but not between ML and MD samplings within the same month (ANOVA, Duncan's test, $\mathrm{p}<0.05$ ). The COSINOR analysis revealed the existence of a significant sinusoidal rhythm of annual plasma $\mathrm{T}$ in female sole $(\mathrm{p}<0.01)$, with a mesor of $0.4 \mathrm{ng} \mathrm{ml}^{-1}$, an amplitude of $0.4 \mathrm{ng} \mathrm{ml}^{-1}$ and an acrophase in February (fig 1c).

A total of six spawning events were observed, from $12^{\text {th }}$ May to $9^{\text {th }}$ June, when temperature ranged from 20 to $21{ }^{\circ} \mathrm{C}$, with a mean volume of $69.2 \pm 44.8 \mathrm{~cm}^{3}$. The total volume of eggs recovered during the spawning period was $415 \mathrm{~cm}^{3}$. In all cases, there was a total absence of egg fertilization. 


\section{Experiment 2: Daily rhythms of plasma sexual steroids $\left(E_{2}\right.$ and $\left.T\right)$ in different seasons}

As to the daily rhythms of $E_{2}$ and $T$, high values were only registered for both at Spring Equinox (fig. 2 and 3). In the other three 24h-samplings (summer and winter solstices and autumn equinox) values were low, and no daily rhythms could be described. In the case of $E_{2}$, at the spring equinox, values varied from $2.1 \pm 1.5 \mathrm{ng} \mathrm{ml}^{-1}$ at $6: 30 \mathrm{~h}$ to $6.6 \pm 2.6 \mathrm{ng} \mathrm{ml}^{-1}$ at 18:30 h (fig 2a), a three-fold increase in 12 hours. The COSINOR analysis revealed the existence of a significant sinusoidal rhythm of daily plasma $E_{2}$ in female sole $(p<0.01)$, with a mesor of $4.4 \mathrm{ng} \mathrm{ml}^{-1}$, an amplitude of $2.0 \mathrm{ng} \mathrm{ml}^{-1}$ and an acrophase at 20:00 h (fig 2e[c2]). As regards to $\mathrm{T}$, values varied between $0.7 \pm 0.2 \mathrm{ng} \mathrm{ml}^{-1}$ at 9:30 and $1.5 \pm 0.6 \mathrm{ng} \mathrm{ml}^{-1}$ at 21:30 h at the spring equinox (fig 3a), a two-fold increase within the same day. The COSINOR analysis revealed the existence of a significant sinusoidal rhythm of daily plasma $T$ in female sole at the spring equinox $(\mathrm{p}<0.01)$ with a mesor of $1.0 \mathrm{ng} \mathrm{ml}^{-1}$, an amplitude of $0.4 \mathrm{ng} \mathrm{ml}^{-1}$ and an acrophase at 21:08 h (fig 3e[c3]).

\section{Experiment 3: Influence of an attenuated thermal cycle on the seasonal production of} plasma sexual steroids $\left(\mathrm{E}_{2}\right.$ and $\left.\mathrm{T}\right)$

In the third experiment, the influence of the natural annual fluctuation of water temperature on the annual rhythm of steroids was studied. For both $E_{2}$ and $T$, a strong influence was seen (fig 4). In the case of the $E_{2}$, the concentration pattern was arrhythmic in the group maintained under an attenuated thermal cycle throughout the year (well-water group), unlike the group maintained under the natural thermocycle (surface water group) (fig 4a). For well-water group, values remained low in all samplings (between $0.2 \pm 0.1 \mathrm{ng} \mathrm{ml}^{-1}$ in autumn and $1.4 \pm 0.4 \mathrm{ng} \mathrm{ml}^{-1}$ in spring), and did not increase in spring like surface water group $\left(5 \pm 0.9 \mathrm{ng} \mathrm{ml}^{-1}\right)$. No significant statistical differences were observed between any of the sampling points in well-water group.

As regards $\mathrm{T}$, once more the concentration rhythm differed between the two groups. There were no statistical differences within the well-water group and consequently no concentration surge in winter and spring as in the surface water group. In the winter sampling, plasma levels were significantly lower $\left(0.3 \pm 0.1 \mathrm{ng} \mathrm{ml}^{-1}\right)$ than those in surface water group $\left(0.9 \pm 0.2 \mathrm{ng} \mathrm{ml}^{-1}\right)$, while in spring the $\mathrm{T}$ concentration rose to reach similar levels to those registered in surface water group. In summer, the values were higher, but not statistically 


\section{Discussion}

This research attempted to detect within-day fluctuations of plasma sex steroids in Senegal sole female, studying the day/night concentrations each month and the seasonal daily rhythms of $E_{2}$ and $T$. The fact that ML/MD differences in steroid concentrations could not be detected in the first experiment does not necessarily mean that they did not exist; they may well have been located at another moment of the day. Actually, the acrophases of the daily rhythms were located at 20:00h in $E_{2}$ and at 21:08h in $\mathrm{T}$, half way between ML and MD. However, this kind of experimental design (the use of two sampling points with $12 \mathrm{~h}$ interval) does permit the acquisition of reliable mean daily values, even though the daily rhythm may shift seasonally.

An annual rhythm for $E_{2}$ and $T$ was observed, with maximum values registered in March, before the spawning period that occurred in May-June, and minimal values in August, when the temperature was highest $\left(25^{\circ} \mathrm{C}\right)$. It is important to note that our samplings were performed around the $25^{\text {th }}$ day of each month, so that high steroid concentrations observed in March corresponded to the end of the month, and probably continued into April. A similar pattern of sex steroids in F1 Senegal sole female was obtained by Guzmán et al. (2008): both steroids reached maximum concentrations in the pre-spawning period (March and April, respectively, for $\mathrm{T}$ and $\mathrm{E}_{2}$ ) and decreased thereafter. As in our study, $\mathrm{T}$ concentrations rose earlier than $E_{2}$, which is normal since $T$ is known to be a biosynthetic precursor of $E_{2}$ (Kagawa et al., 1982). The peak of $E_{2}$ in anticipation of the spawning season is in accordance with the established role of $\mathrm{E}_{2}$ in initiating and maintaining vitellogenesis and regulating vitellogenin synthesis (Wallace, 1985). In the case of a Senegal sole wild broodstock, the maximum values of $E_{2}$ and $T$ were registered slightly earlier, in February, but in this case the spawning season also started earlier, in January in one year and in March the next (GarcíaLópez et al., 2006b). These results are basically in accordance with ours, despite the slight differences in timing, which may have been due to different years, different geographic or climate conditions, and the origin of the broodstock.

In other teleost species, annual steroid rhythms have been detected. For example, in common dentex (Dentex dentex), $\mathrm{E}_{2}$ and $\mathrm{T}$ levels peaked in April, coinciding with the spawning season (Pavlidis et al., 2000), or in European sea bass (Dicentrarchus labrax) in which sex steroids reached maximum values from December to February (Prat et al., 1990, 
the synchronization of this phenomenon to seasonal environmental changes, according to species requirements.

In the second experiment, a daily steroid rhythm was described in Senegal sole. Daily rhythms of both $E_{2}$ and $T$ plasma concentrations were observed during the spring equinox, with acrophases occurring in the evening. In the case of E2 concentrations, a three-fold increase was observed within $12 \mathrm{~h}$, while T concentrations increased two-fold. These results highlight the importance of the time of the day when sampling for steroids. To avoid inconsistencies, these fluctuations must be considered, as well as their seasonality. Furthermore, for hormonal induction studies, the time of the day when the hormone is administered should be carefully considered, since different timing may lead to different responses.

The timing of the acrophases of both steroids was 20:00 $\mathrm{h}\left(\mathrm{E}_{2}\right)$ and 21:08 $\mathrm{h}(\mathrm{T})$, which curiously approached to the acrophase of the daily spawning rhythm in this species. Recent research from our group, revealed a daily spawning rhythm in senegal sole during spring, its acrophase occurring at night, around 23:00h (Oliveira et al., 2008). These findings suggest a strong nocturnal pattern in the reproduction of this species, matching the nocturnal behavioral patterns of sole (Bayarri et al 2004a), which has never been regarded to date.

The daily variations in sexual steroids in fish are short-term fluctuations, which are associated with the maturation of different groups of oocytes at intervals of days during the spawning season (Peter and Yu, 1997). In other fish species, daily patterns of sexual steroids have been described. According to Bayarri et al. (2004b), in sea bass, Dicentrarchus labrax, besides a daily rhythm of plasma $\mathrm{T}$ concentration in males, there was also evidences of daily rhythms of plasma LH and of pituitary LH and GnRH. In the case of plasma LH, the daily rhythm was in phase with the plasma melatonin rhythm, presenting higher values during the night, after the nocturnal increase of melatonin. In red sea bream (Pagrus major) females, plasma $E_{2}$ levels reached a peak at 7:00 h in fish with pre-mature stage oocytes, out of phase with spawning, which mainly occurred between 18:00 h and 19:00 h. (Matsuyama et al., 1988). Also in snapper (Pagrus auratus) there was evidence that levels of both $\mathrm{E}_{2}$ and $\mathrm{T}$ changed according to the time of day during the spawning season (Carragher and Pankhurst, 1993). Finally, the Japanese whiting (Sillago japonica) also presented a diurnal pattern of plasma $\mathrm{E}_{2}$ (Matsuyama et al., 1990).

Curiously enough, the acrophases in the annual and daily rhythms of steroids preceded those of melatonin by Vera et al. (2007). In the annual rhythm the acrophase of the melatonin 
and T. As regards the spring daily rhythm, the same pattern was repeated: the melatonin acrophase was located at 0:30 h, exactly 4.5 and $5.5 \mathrm{~h}$ after $\mathrm{E}_{2}$ and $\mathrm{T}$ acrophases respectively. This appears to be the repetition of the same phenomenon at different scales.

Seasonal changes in water temperature seemed to be a key player in synchronizing annual rhythms of steroids in female sole. We observed that the steroid rhythm disappeared in conditions of attenuated thermo cycle (well-water group), since the annual pattern of plasma $E_{2}$ and $T$ did not present the typical spring surge. This agrees with the fact that well-water group did not spawn during the experimental period. In this group the values of $\mathrm{E}_{2}$ and $\mathrm{T}$ did not increase more than $1.4 \pm 0.4$ and $0.7 \pm 0.1 \mathrm{ng} \mathrm{ml}^{-1}$, respectively, while in surface water group (natural fluctuating temperature) they reached values of $5 \pm 0.9$ and $1.1 \pm 0.2 \mathrm{ng} \mathrm{ml}^{-1}$, respectively. According to Patiño and Thomas (1990) and Patiño et al. (2001), a certain threshold of $E_{2}$ and $T$ plasma levels is required to trigger final oocyte maturation, which may explain the lack of spawning events in well-water group. In addition, water temperature is known to have direct effects on certain aspects of steroidogenesis and rates of steroid hormone metabolism and clearance in teleosts (Van Der Kraak and Pankhurst, 1997; Pankhurst and Porter, 2003), which, under suboptimal conditions, may have the potential to disrupt oocyte development. In a recent study (García-López et al., 2006a), a group of sole were maintained under natural photoperiod and attenuated thermo-cycle $\left(18-20{ }^{\circ} \mathrm{C}\right)$, and in this case females did present $\mathrm{E}_{2}$ and $\mathrm{T}$ rhythms, with a premature reduction and lower values in comparison with the control group, but with a parallel surge and a peak in both steroid concentrations. The same did not happen in our study, since values remained statistically low during all seasons, and no surge was observed in any of the steroid concentrations. These differences could be justified by differences in temperature fluctuations, rearing conditions, origin of sole or geographic location (Mediterranean vs Atlantic). Although the steroid rhythm differed between these two sole groups maintained under conditions of minimal water temperature fluctuation, in both cases animals failed to spawn, which highlights the importance of the temperature cycle for the resumption of spawning.

According to Vera et al. (2007), the water temperature modulates nocturnal melatonin rhythm in Senegal sole, and in the absence of the natural fluctuating regime of temperature, nocturnal plasma concentrations of this hormone were constant during the whole year. As this hormone is known as a "Clock/Calendar" hormone (Reiter, 1993), this could explain the absence of steroid rhythm: without the melatonin signal, fish do not receive seasonal information, and can not synchronize rhythms, including reproduction. Furthermore, Amano 
administration. Melatonin treatment had a stimulatory effect on the gonadosomatic index, follicle stimulating hormone contents, and plasma $\mathrm{T}$ and 11-ketotestosterone concentrations. In summary, we may conclude that sole revealed an annual rhythm in plasma $E_{2}$ and $\mathrm{T}$, their acrophases being located in February, anticipating the spawning season (May-June). At the spring equinox, a daily rhythm of both these steroids was described, with an acrophase located at 20:00 $\mathrm{h}$ for $\mathrm{E}_{2}$ and 21:08 $\mathrm{h}$ for $\mathrm{T}$, preceding again spawning, which occurs during the night. In addition, the annual fluctuating water temperature seemed to be a crucial synchronizer of the reproduction rhythms in Senegal sole female, since, in the absence of this environmental signal, the steroid rhythm disappeared, and spawning did not occur.

\section{Acknowledgments}

This research was funded by the MEC (Spanish Ministry of Education and Science) project Reprosolea (AGL 2004-07984-C02-01) to FJSV and by the MAPA (Ministry of Agriculture, Fisheries and Food) project JACUMAR 2006 (II National plan for the cultivation of sole) to EM. CO received a FPI Fellowship from the MEC. The authors would also like to thank PISCIMAR S.L. for the use of its facilities and fish during sampling.

\section{References}

Aguillero, M.J., Anguis, V., Cañavate, J.P., Martínez-Rodríguez, G., Mylonas, C.C., Cerdà, J., 2006. Induction of spawning of captive-reared Senegal sole (Solea senegalensis) using different administration methods for gonadotropin-releasing hormone agonist. Aquaculture 257, 511-524.

Amano, M., Iigo, M., Ikuta, K., Kitamura, S., Yamada, H., Yamamori, K., 2000. Roles of melatonin in gonadal maturation of underyearling precocious male masu salmon. Gen. Comp. Endocrinol.

Anguis, V., Cañavate, J.P., 2005. Spawning of captive Senegal sole (Solea senegalensis) under a naturally fluctuating temperature regime. Aquaculture 243, 133-145.

Bayarri, M.J., Muñoz-Cueto, J.A., Lòpez-Olmeda, J.F., Vera, L.M., Rol de Lama, M.A., Madrid, J.A., Sánchez-Vázquez, F.J., 2004a. Daily locomotor activity and melatonin rhythms in Senegal sole (Solea senegalensis). Physiol. Behav. 81, 577-583.

Baynes, S.M., Howell, B.R., Beard, T.W., 1993. A review of egg production by captive sole, Solea solea (L.). Aquac. Fish. Manage. 24, 171-180. 
Bromage, N., Porter, M., Randall, C., 2001. The environmental regulation of maturation in farmed finfish with special reference to the role on photoperiod and melatonin. Aquaculture 197, 63-98.

Carragher, J.F., Pankhusrt, N.W., 1993. Plasma levels of sex steroids during sexual maturation of snapper, Pagrus auratus (Sparidae), caught from the wild. Aquaculture 109, 375-388.

Díez, A., 2007. Representación grafica y análisis de datos en cronobiología. In: Madrid, J.A., Rol de Lama, M.A. (Eds.), Cronobiología básica y clínica. Editec@red S.L., Madrid, pp. 84-121.

Dinis, M.T., Ribeiro, L., Soares, F., Sarasquete, C., 1999. A review on the cultivation potential of Solea senegalensis in Spain and in Portugal. Aquaculture 176, 27-38.

EEC, 1986. Council Directive 86/609 EEC for the protection of animals used for experimental and other scientific purposes. Official Journal L358 (18/12/1986), 1-28.

Falcón, J., Besseau, L., Sauzet, S., Bouef, G., 2007. Melatonin effects on the hypothalamus-pituitary axis in fish. Trends Endocrinol. Metabol. 18, 81-88.

García-López, A., Pascual, E., Sarasquete, C., Martínez-Rodríguez, G., 2006a. Disruption of gonadal maturation in culture Senegalese sole Solea senegalensis Kaup by continuous Light and/or constant temperature regimes. Aquaculture 261, 789-798.

García-López, A., Anguis, V., Couto, E., Canário, A.V.M., Cañavate, J.P., Sarasquete, C., MartínezRodrígues, G., 2006b. Non-invasive assessment of reproductive status and cycle of sex steroid in a captive wild broodstock of Senegalese sole Solea senegalensis (Kaup). Aquaculture 254, 583-593.

García-López, A., Couto, E., Canário, A.V.M., Sarasquete, C., Martínez-Rodrígues, G., 2007. Ovarian development and plasma sex steroid levels in cultured female Senegalese sole Solea senegalensis. Comp. Biochem. Physiol. A 146, 342-354.

Guzmán, J.M., Marull, E., Ramos, J., Mylonas, C.C., Olmos, V., Mañanóz, E., 2005. Indución hormonal a la puesta del lenguado senegalés (Solea senegalensis) mediante la administración de sistemas de GnRHa de liberación sostenida. Actas X Congreso Nacional de Acuicultura. Universidad Politécnica de Valencia, Valencia, Spain, pp. 490-491.

Guzmán, J.M., Norberg, B., Ramos, J., Mylonas, C.C., Mañanóz, E., 2008. Vitellogenin, steroid plasma levels and spawning performance of cultured female Senegalese sole (Solea senegalensis). Gen. Comp. Endocrinol. 156, 285-297.

Hontela, A., Stacey, N.E., 1990. Cyprinidae. In: Munro, A.D., Scott, A.P., Lam, T.J. (Eds.), Reproductive seasonality in teleosts: environmental influences. CRC Press, Boca Raton, FL, pp. 53-77.

Kagawa, H., Young, G., Nagahama, Y., 1982. Estradiol 17- $\beta$ production in isolated amago salmon (Onchorhynchus rhodurus) ovarian follicles and its stimulation by gonadotropins. Gen. Comp. Endocrinol. 47, 361-365. 
Kobayashi, M., Aida, K., Furukawa, K., Kok Law, Y., Moriwaki, T., Hanyu, I., 1988. Development of sensitivity to maturation-inducing steroids in the oocytes of the daily spawning teleost, the kisu Sillago japonica. Gen. Comp. Endocrinol. 72, 264-271.

Kobayashi, M., Aida, K., Hanyu, I., 1989. Involvement of steroid hormones in the preovulatory gonadotropin surge in female goldfish. Fish. Physiol. Biochem. 7, 141-146.

Lincoln, G.A., 2006. Melatonin entrainment of circannual rhythms. Chronobiol. Int. 23, 301-306.

Mañanós, E.L., Zanuy S., Carrillo, M., 1997. Photoperiodic manipulations of the reproductive cycle of sea bass (Dicentrarchus labrax) and their effects on gonadal development, and plasma 17betaestradiol and vitellogenin levels. Fish Physiol. Biochem. 16, 211-222.

Matsuyama, M., Adachi, S., Nagahama, Y., Matsuura, S., 1988. Diurnal rhythm of oocyte development and plasma steroid hormone levels in the female red sea bream, Pagrus major, during the spawning season. Aquaculture 73, 357-372.

Matsuyama, M., Adachi, S., Nagahama, Y., Maruyama, K., Matsura, S., 1990. Diurnal rhythm of serum hormone levels in the Japanese whiting, Sillago japonica, a daily spawning teleost. Fish. Physiol. Biochem. 8, 329-338.

Merson, R.R., Casey, C.S., Martinez, C., Soffientino, B., Chandlee, M., Specker, J.L., 2000. Oocyte development in summer flounder: seasonal changes and steroid correlates. J. Fish Biol. 57, 182196.

Oliveira, C., Ortega, A., López-Olmeda, J.F., Vera, L.M., Sánchez-Vázquez, F.J., 2007. Influence of constant light and darkness, light intensity and spectrum on plasma melatonin rhythms in Senegal sole. Chronobiol. Int. 24, 615-627.

Oliveira, C., Dinis, M.T., Soares, F., Cabrita, E., Pousão-Ferreira, P., Sánchez-Vázquez, F.J., 2008. Lunar and daily spawning rhythms of Senegal sole (Solea senegalensis). Submitted to Aquaculture.

Pankhurst, N.W., Porter, M.J.R., 2003. Cold and dark warm and light: variations on the theme of environmental control of reproduction. Fish Physiol. Biochem. 28, 385-389.

Patiño, R., Thomas, P., 1990. Effects of gonadotropin on ovarian intrafollicular processes during the development of oocytes maturational competence in a teleost, the Atlantic croaker: evidence for two distinct stages of gonadotrophic control of oocytes maturation. Biol. Reprod. 43, 818-827.

Patiño, R., Yashizaki, G., Thomas, P., Kagawa, H., 2001. Gonadotrophic control of ovarian follicle maturation: the two stage concept and its mechanism. Comp. Biochem. Physiol. 129, 427-439.

Pavlidis, M., Greenwood, L., Mourot, B., Kokkari, C., Le Menn, F., Divanach, P., Scott, A.P., 2000. Seasonal variations and maturity stages in relation to differences in serum levels of gonadal steroids, vitellogenin, and thyroid hormones in the common dentex (Dentex dentex). Gen. Comp. Endocrinol. 118, 14-25.

Peter, R.E., Yu, K.L., 1997. Neuroendocrine regulation of ovulation in fishes: basic and applied aspects. Rev. Fish Biol. Fish. 7, 173-197. 
Prat, F., Zanuy, S., Carrillo, M., De Mones, A., Fostier, A., 1990. Seasonal changes in plasma levels of gonadal steroids of sea bass, Dicentrarchus labrax L. Gen. Comp. Endocrinol. 78, 361-373.

Reiter, R.J., 1993. The melatonin rhythm: both a clock and a calendar. Experientia 49, 654-664.

Saavedra, M., Pousão-Ferreira, P., 2006. A preliminary study on the effect of lunar cycles on the spawning behaviour of the gilt-head sea bream, Sparus aurata. J. Mar. Biol. Ass. U.K. 86, 899901.

Takemura, A., Rahman, M.S., Nakamura, S., Ju Park, Y., Takano, K., 2004. Lunar cycles and reproductive activity in reef fishes with particular attention to rabbitfishes. Fish Fish. 5, 317328.

Van Der Kraak, G., Pankhurst, N.W., 1997. Temperature effects on the reproductive performance of fish. In: Wood, C.M., MaDonald, D.G., (Eds.), Global warming: implications for freshwater and marine fish. Cambridge University press, Cambridge, pp.159-176.

Vera, L.M., Oliveira, C., Lopez-Olmeda, J.F., Ramos, J., Mañanós, E., Madrid, J.A., SánchezVázquez, F.J., 2007. Seasonal and daily plasma melatonin rhythms and reproduction in Senegal sole kept under natural photoperiod and natural or controlled water temperature. J. Pineal Res. $43,50-55$.

Wallace, R.A., 1985. Vitellogenesis and oocyte growth in nonmammalian vertebrates. In: Browder, L.W. (Eds.), Dev. Biol. Plenum Publishing Corporation, pp. 127-177.

Yaron, Z., Gur, G., Melamed, P., Rosenfeld, H., Elizur, A., Levavi-Sivan, B., 2003. Regulation of fish gonadotropins. Int. Rev. Citol. 225, 131-185.

\section{Figure Captions}

Figure 1. Annual rhythm of plasma estradiol (a) and testosterone (b) levels at mid-dark (black bars) and mid-light (white bars); and polar representation of the COSINOR analysis, depicting clockwise the annual cycle (c). In (a) and (b), the months are indicated at the bottom and grey horizontal bars indicate spawning period. Upper line represents water temperature and different letters indicate statistically significant differences between sampling months (MD and ML values pooled) (ANOVA, Duncan's test, $\mathrm{P}<0.05$ ). No differences were detected between MD and ML within the same month. In (c), the vectors point to the moment each acrophase occurred, and its length represents the amplitude. The ellipses represent the confidence interval.

Figure 2. Daily plasma estradiol rhythm at the spring equinox (a), summer solstice (b), autumn equinox (c) and winter solstice (d), and polar representation of the Cosinor analysis for spring equinox, depicting clockwise the daily cycle (e). In (a) to (d) the black and white 
510 bars correspond to sampling points during the day or night, respectively. The continuous line 511 in Spring equinox graph represents the adjustment of the sinusoidal rhythm. Water 512 temperature on the sampling day is indicated at the bottom. In (e) the vector points to the 513 moment the acrophase occurred, and its length represents the amplitude. The ellipse 514 represents the confidence interval.

\section{5}

516 Figure 3. Daily plasma testosterone rhythm at the spring equinox (a), summer solstice (b), 517 autumn equinox (c) and winter solstice (d) and polar representation of the Cosinor analysis for 518 spring equinox, depicting clockwise the daily cycle (e). In (a) to (d) the black and white bars 519 correspond to sampling points during the day or night, respectively. The continuous line in 520 Spring equinox graph, represents the adjustment of the sinusoidal rhythm. Water temperature 521 on the sampling day is indicated at the bottom. In (e) the vector points to the moment the 522 acrophase occurred, and its length represents the amplitude. The ellipse represents the 523 confidence interval.

525 Figure 4. Comparison between plasma estradiol (a) and testosterone (b) levels from fish 526 submitted to the environmental temperature cycle (mid-dark: black bars, mid-light: white 527 bars) and reared under attenuated thermo-cycle (mid-dark: dotted black bars, mid-light: dotted 528 white bars). The upper continuous and dotted lines represent the water temperature of fish 529 reared under natural and attenuated thermo-cycle, respectively. Different letters indicate 530 statistically significant differences (ANOVA, Duncan's test, $\mathrm{P}<0.05$ ). 

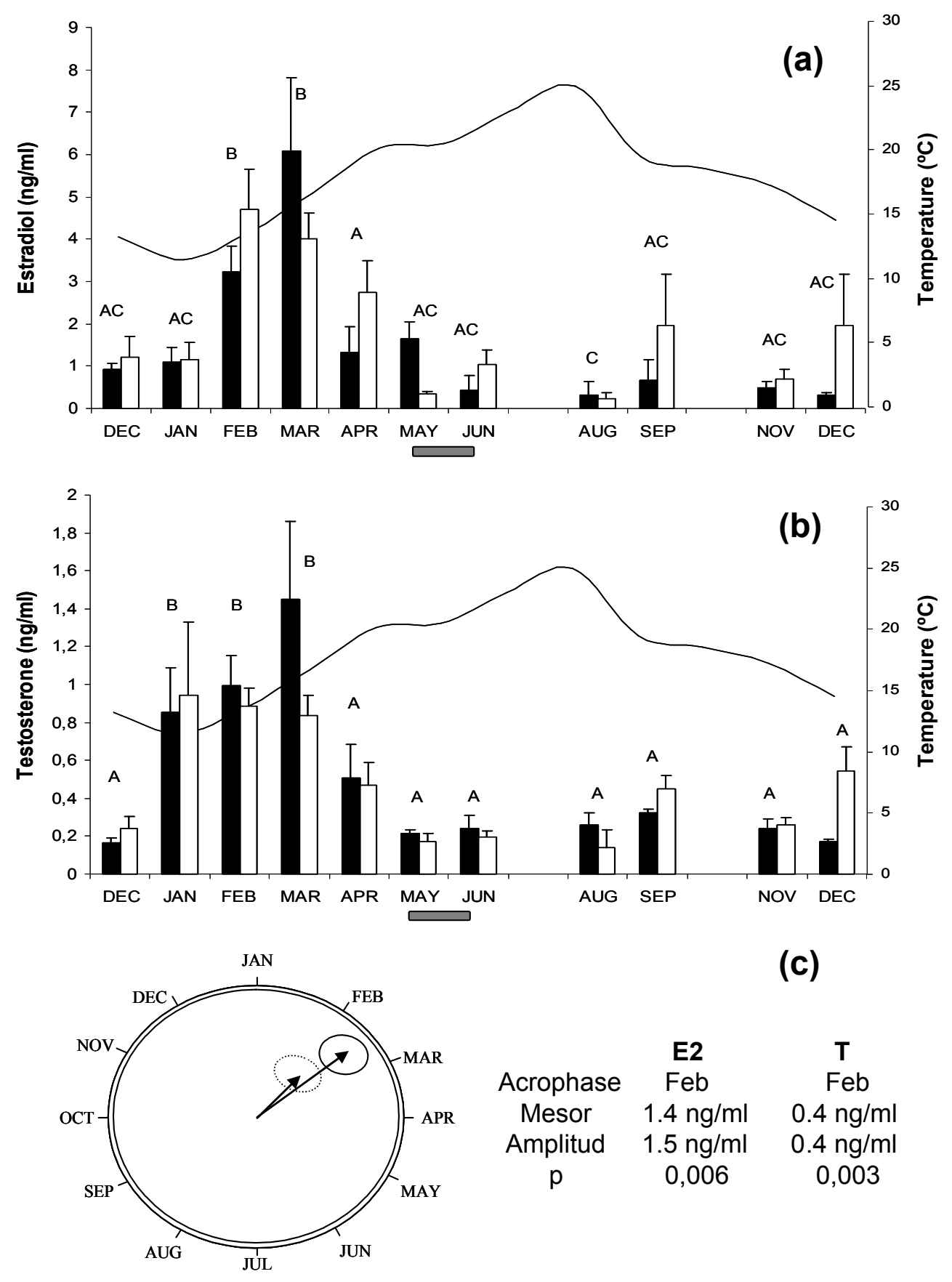

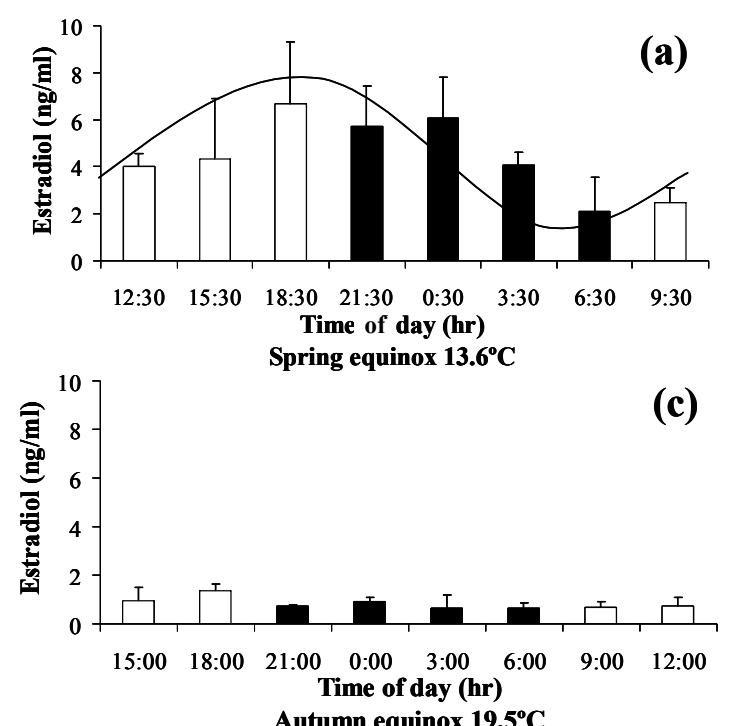

Autumn equinox $19.5^{\circ} \mathrm{C}$

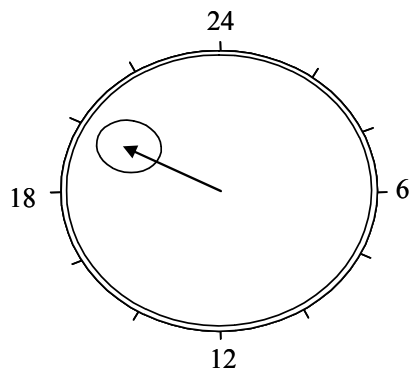

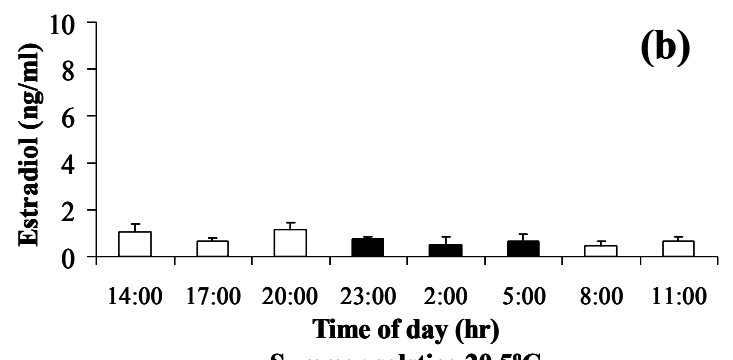

Summer solstice $20.5^{\circ} \mathrm{C}$

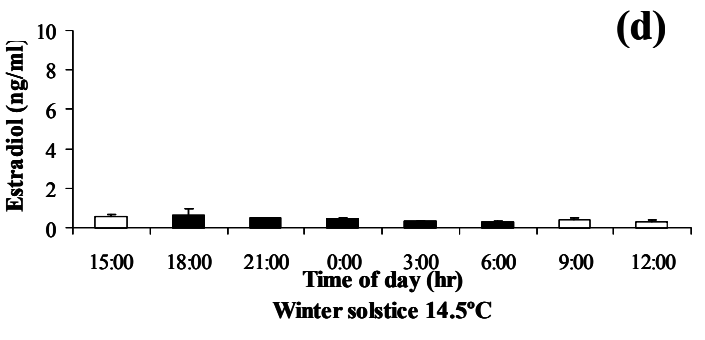

(e)

E2

Acrophase 20:00h

Mesor $\quad 4.4 \mathrm{ng} / \mathrm{ml}$

Amplitud $\quad 2.0 \mathrm{ng} / \mathrm{ml}$

p $\quad 0,005$ 

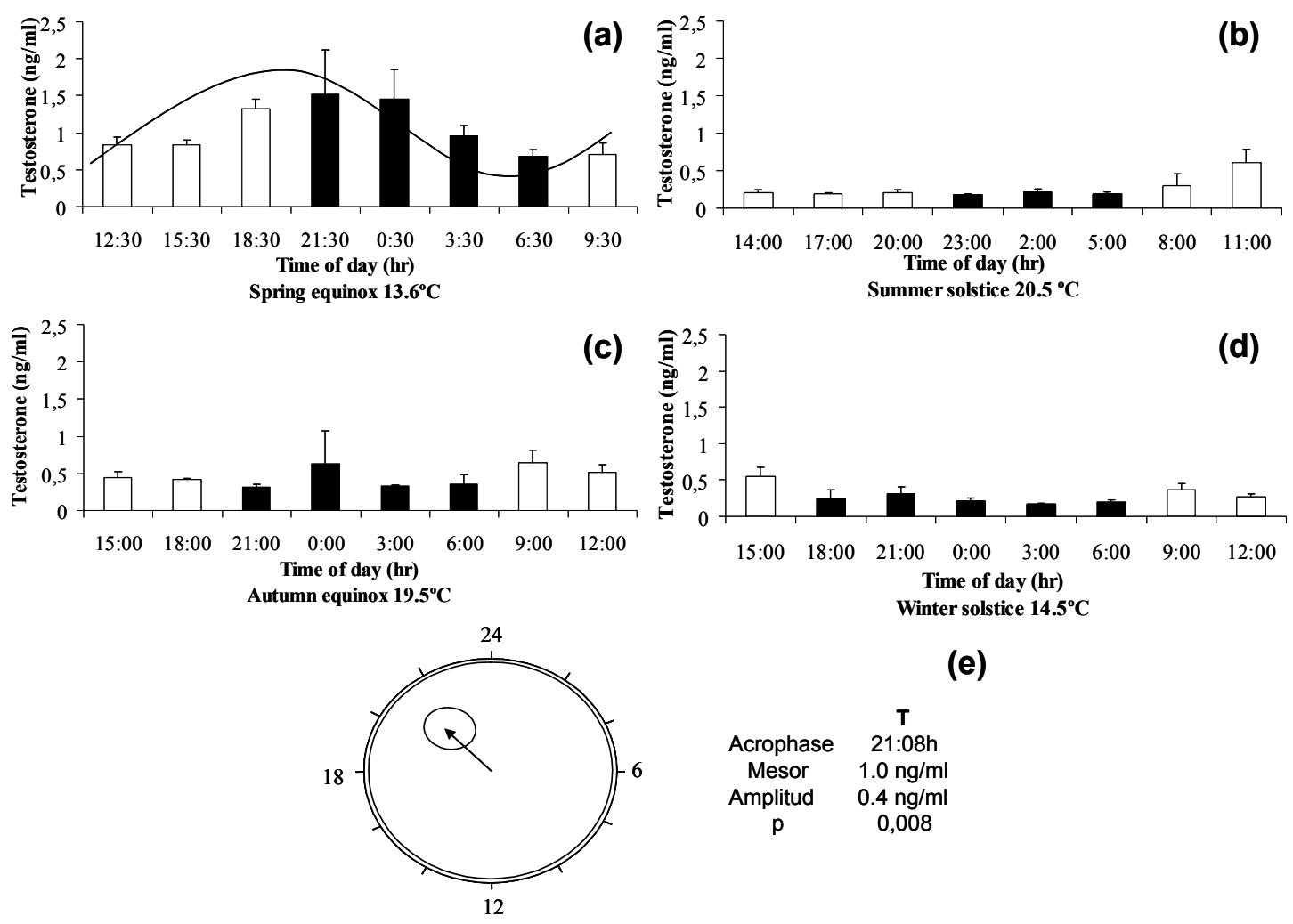

(e)

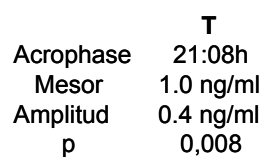



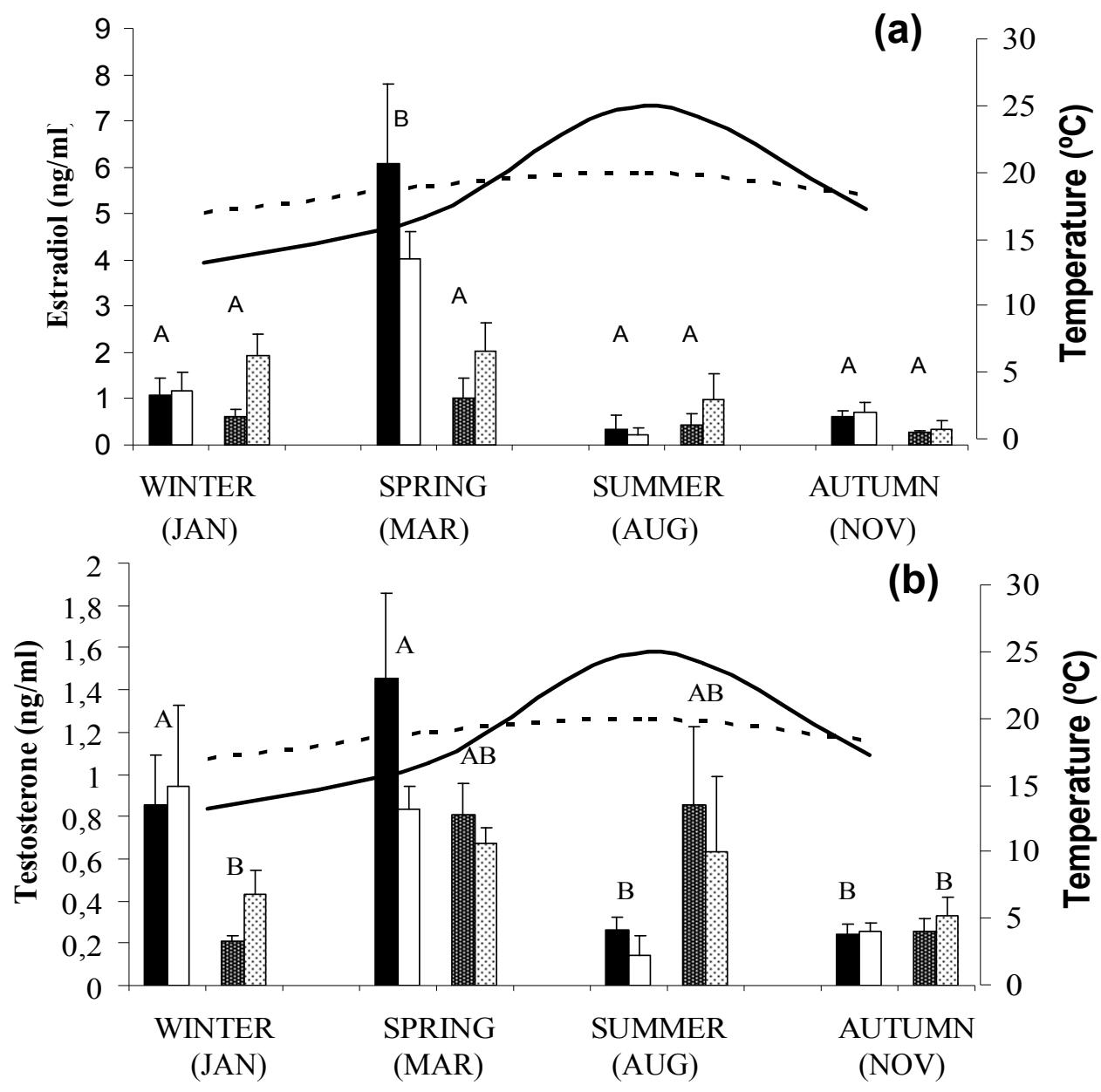